\title{
0 Twitter como fonte de História Oral: análise da @vozdacomunidade na ocupação do Complexo do Alemão
}

\author{
Poliana LOPES \\ Denise Castilhos DE ARAÚJO²
}

Resumo

Este artigo pretende analisar as relações entre o Twitter e estudos historiográficos, verificando se as publicações na rede social podem servir como fonte histórica quando usadas para narrar acontecimentos. Propõe-se uma pesquisa de natureza aplicada com abordagem qualitativa que associa as reflexões de Thomson (2000), Joutard (2000) e Santaella e Lemos (2010) ao corpus, composto pelas publicações de @vozdacomunidade durante a ocupação do Complexo do Alemão em 2010. Entende-se, a partir da análise, que quando o Twitter agrega relatos, estes podem servir como documento de História Oral, dando voz a pessoas comuns.

Palavras-chave:

Comunicação; História Oral; Twitter.

\section{Twitter as Oral History's source: analysis of @vozdacomunidade during the occupation of the Complexo do Alemão}

\footnotetext{
Abstract

This article aims to analyze the relationship between Twitter and historiographical studies, checking if publications in the social network can serve as a historical source when used to

1Doutoranda e Mestre em Processos e Manifestações Culturais (Universidade Feevale), Jornalista (Unisinos) especialista em História, Comunicação e Memória do Brasil Contemporâneo (Universidade Feevale). Bolsista Prosup/Capes. E-mail: poli.lopess@gmail.com.

2 Orientadora: Doutora em Comunicação Social (PUCRS); professora do PPG em Processos e Manifestações Culturais e dos cursos de Comunicação Social e Design; pesquisadora do Grupo de Estudos Cultura e Memória da Comunidade na Universidade Feevale. E-mail: deniseca@ feevale.br.
} 
narrate events. It's proposed a research with qualitative approach that associates the reflections of Thomson (2000), Joutard (2000) and Santaella and Lemos (2010) to the corpus, which brings @ vozdacomunidade publications made during the occupation of the Complexo do Alemão in 2010. It's understood, from the analysis, that when Twitter adds reports, these can serve as oral history document, giving voice to ordinary people.

Keywords:

Communication; Oral History; Twitter.

\section{Twitter como fuente de Historia Oral: análisis de @vozdacomunidade en la ocupación del Complexo do Alemão}

\section{Resumen}

Este artículo tiene como objetivo analizar la relación entre Twitter y los estudios historiograficos, asegurándose de que las publicaciones en la red social pueden servir como fuente histórica cuando es utilizada para narrar eventos. Se propone aplicar un enfoque de naturaleza cualitativa que asocia el reflexiones Thomson (2000), Joutard (2000) y Santaella y Lemos (2010) en el corpus, compuesto por publicaciones de @ vozdacomunidade durante la ocupación del Complexo do Alemão en 2010. Se entiende, a partir del análisis, que cuando Twitter añade informes, estos pueden servir como documento de la historia oral, dando voz a toda la gente.

Palabras clave:

Communicación; Historia Oral; Twitter.

\section{Introdução}

Dados do Ibope (2014) apontam que 53\% da população brasileira acessa regularmente a internet, que é a primeira fonte utilizada na busca por informações por 47\% da população. Entre os jovens de 15 a 32 anos, 90\% da população acessa a internet regularmente, $93 \%$ navegam em sites de redes sociais e $43 \%$ consideram a internet sua principal fonte de entretenimento (IBOPE, 2014). O crescimento da internet e o surgimento de novas plataformas estão transformando a forma de relato e registro da história do tempo presente, não apenas do país, mas de todo o mundo. Um exemplo recente é a caminhada dos refugiados sírios de Budapeste (Hungria) até a Áustria, em 2015, que foi relatada, via redes sociais digitais, e pôde ser acompanhada por pessoas de todo o mundo pela hashtag \#marchofhope.

Uma das principais ferramentas usadas para esses registros é o Twitter, site de 
rede social gratuito no qual os usuários escrevem mensagens curtas de até 140 caracteres (tweets) que são enviadas para seus seguidores (followers). Santaella e Lemos (2010) destacam que a rede é reconhecida principalmente pelo caráter always ${ }^{3}{ }^{3}$ que a associação entre mobilidade e temporalidade permite, assim como a não necessidade de relação off-line.

Ao ser usado para narrar acontecimentos, o Twitter tende a se tornar um agregador de relatos, os quais podem servir de fonte histórica. Neste artigo, pretende-se analisar o papel do Twitter $^{4}$ na cobertura de eventos em tempo real, visando compreender seu papel na construção da História recente do Brasil. Desta forma, buscase responder, a partir do uso do método comparativo, se o Twitter pode ser considerado uma fonte de História Oral ao assumir o papel de relato do cotidiano. Também se pretende, aqui, apontar formas de uso das mídias sociais, em especial o Twitter, como espaços que garantam a validade do relato enquanto fonte oral.

Em relação aos procedimentos metodológicos, trata-se de uma pesquisa de natureza aplicada com abordagem qualitativa, que observa e analisa o corpus selecionado a partir do referencial teórico apresentado. Para a coleta de dados, foi feita pesquisa bibliográfica norteada a partir de três eixos: História Oral, redes sociais digitais (com foco no Twitter) e narrativa dos acontecimentos. O corpus é constituído por pesquisa documental realizada nas publicações do perfil @ vozdacomunidade no Twitter durante a ocupação do Complexo do Alemão (2010).

Este artigo divide-se em três partes. Na primeira, há a apresentação das características do Twitter e o seu papel das redes sociais digitais. A segunda parte aproxima o Twitter dos conceitos de História Oral, e a terceira, apresenta a aplicação dos conceitos sobre o corpus, composto por publicações feitas no Twitter durante a ocupação do Complexo do Alemão (Rio de Janeiro), ocorrida em 2010, por três moradores do Morro do Adeus ligados ao jornal Voz da Comunidade. O grupo usou o microblogging ${ }^{5}$ para relatar, em tempo real, o que acontecia no local. Os tweets tiveram alto engajamento, da comunidade e de pessoas de todo o país - incluindo celebridades ligadas à cidade -, e foram transformados em fonte para a cobertura jornalística do fato por outros veículos.

\footnotetext{
${ }^{3}$ Sempre conectado, em tradução livre.

4 Mídia social também conhecida como microblogging, que permite ao usuário escrever o que está acontecendo em até 140 caracteres. As mensagens são mostradas em tempo real, destacando-se pelo compartilhamento de notícias e informações de rápida leitura (LIMA, 2011).

${ }^{5}$ Cobertura pelos perfis@ @ozdacomunidade, @Rene_Silva_RJ, @IgorComunidade e @JackComunidade (GLOBO, 2010b).
} 


\section{Redes sociais digitais: Twitter}

Para compreender como a rede social digital Twitter pode ser usada como fonte historiográfica, é necessário primeiro compreender seu funcionamento e apropriações de uso. Isto porque as redes sociais digitais demonstram a "extraordinária capacidade dos indivíduos em gerar, difundir e trocar significados na comunicação interpessoal coletiva, em um sistema massivo de rede e em tempo real, no qual tudo tende a estar conectado" (GARCÍA; DALY; SUPOVITZ, 2015, p. 55, tradução nossa) ${ }^{6}$.

Lemos e Lévy (2010) apontam que o uso das redes sociais digitais não se resume à troca de banalidade, pois há um crescente uso e produção de conteúdo, o qual vem elevando a qualidade das informações trocadas entre usuários. A ampliação de seu uso é a responsável por uma onda ainda não perfeitamente mensurável, definida pelos autores como a "liberação da emissão", que inclui não só a palavra escrita, mas também sons, fotos e vídeos que são distribuídos livremente entre pessoas.

Este artigo detém a atenção sobre o Twitter, rede social digital gratuita, na qual os usuários escrevem mensagens curtas de até 140 caracteres (tweets), que são enviadas para seguidores (followers). Um tweet permite a adição de texto, imagem, vídeo, links e também hashtags, que são palavras ou frases precedidas pelo símbolo \#, que converte o texto em metadado. Usar as hashtags permite a indexação de determinada temática, visando à verificação quantitativa e à compreensão qualitativa das informações do restante do conteúdo do tweet que está associado a elas.

Twitter é atualmente a mídia social mais rápida, simples e econômica, pela qual circula todo o tipo de informação, notícias, ideias, eventos, boatos, materiais multimídia, etc., emitidos a partir de qualquer ambiente profissional ou outras mídias sociais em tempo real. Assim, no Twitter cruzam tanto os meios profissionais da comunicação social (televisão, jornais, revistas, rádio, etc.) quanto qualquer outra mídia social (Facebook, Instagram, Youtube, Flickr, blogs, fóruns, etc.), parte de um vasto registro de tipos de perfis de usuário (indivíduos, ONGs, instituições governamentais, meios de comunicação, grupos de pressão, os periódicos científicos, empresas, marcas, etc.). (GARCÍA; DALY; SUPOVITZ, 2015, p. 57, tradução nossa). ${ }^{7}$

\footnotetext{
6 "Extraordinaria habilidad de las personas para generar, difundir e intercambiar significados en la comunicación interpersonal colectiva, en un sistema masivo en red y en tiempo real donde todo tiende a estar conectado" (GARCIA; DALY; SUPOVITZ, 2015, p. 55).

7 “Twitter es en la actualidad el medio social más rápido, simple y económico por donde circula todo tipo de informaciones, noticias, ideas, eventos, rumores, materiales multimedia, etc. emitido desde cualquier medio profesional $\mathrm{u}$ otros medios sociales en tiempo real. Así, en Twitter interseccionan tanto medios profesionales (televisión, prensa escrita, revistas, radio, etc.) como cualquier otro medio social (Facebook, Instagram, Youtube, Flickr, blogs, foros, etc.) de un muy amplío registro de tipologías de perfiles de usuarios (individuos, ONGs, entidades gubernamentales, medios de comunicación de masas, grupos de presión, revistas científicas, empresas, marcas, etc.)" (GARCIA, DALY E SUPOVITZ, 2015, p. 57).
} 
No mundo, o Twitter tem 241 milhões de usuários ativos por mês. No Brasil são cerca de 40 milhões de usuários ativos, o que representa cerca de $20 \%$ da população brasileira - ou 38\% dos usuários de internet no País. Desse total, $80 \%$ acessa o microblogging por celular ou tablet, o que enfatiza o caráter móvel e a comunicação em tempo real da rede. (PORT, 2015)

Segundo Israel (2010, p. 5), há diferentes interesses e objetivos entre os usuários do Twitter, que "tuitam para arrecadar contribuições para uma causa, para fazer o governo tomar uma atitude, para encontrar e distribuir notícias; para construir redes pessoais ou profissionais ou apenas para matar um pouco de tempo com as pessoas que mais gostam".

Santaella e Lemos (2010) apontam que um diferencial do Twitter é que ele une a mobilidade (permitida pela associação do crescimento do número de smartphones ativos às melhorias de sinal de internet móvel) à temporalidade do caráter always on ${ }^{8}$ inerente às redes sociais 3.0. Ele é "uma verdadeira ágora digital global: universidade, clube de entretenimento, 'termômetro' social e político, instrumento de resistência civil, palco cultural, arena de conversações contínuas" (SANTAELLA; LEMOS, 2010, p. 66).

\section{Aproximação e compreensão da História Oral}

Para compreender a relação entre Twitter e relato histórico, é preciso primeiro entender porque os relatos de cidadãos comuns podem se tornar relevantes para a construção da história. Afinal, até as décadas de 1920 e 1930 as situações históricas analisadas tinham como foco o jogo de poder entre grandes - países e homens.

Foi quando Marc Bloch e Lucien Febvre, ao fundarem a revista Annales - e a Escola de Annales -, entenderam ser necessária uma história mais abrangente e totalizante, pois o homem era e se sentia um ser cuja complexidade não poderia ser reduzida a esse jogo. A partir desse movimento surge, nos anos 1970, a Nova História, conceito creditado à terceira geração dos Analles, conduzida por Jacques Le Goff. (BURKE, 1992).

Uma das novas perspectivas apresentadas pela Nova História é a História Oral, definida como um método que utiliza entrevistas com participantes dos eventos do passado visando sua reconstrução. Ela foi estabelecida em 1948, quando o historiador

\footnotetext{
${ }^{8}$ Sempre conectado, em tradução livre.
} 
Allan Nevins começou a gravar as memórias de pessoas importantes da vida americana (THOMSON, 2000).

Segundo Ferreira (1998, p. 4), esse programa de entrevistas, que visava recuperar informações sobre a atuação dos grupos dominantes norte-americanos, ajudou a constituir o Columbia Oral History Office, o qual foi modelo para outros centros criados nos anos 1950 em bibliotecas e arquivos nos Estados Unidos. A autora destaca que o "primeiro ciclo de expansão do que se chamou de História Oral privilegiou o estudo das elites e se atribuiu a tarefa de preencher as lacunas do registro escrito através da formação de arquivos com fitas transcritas".

Com o crescimento do uso de fontes orais na historiografia registrado nos anos 1950 e 1960, passou-se também a abordar a visão dos excluídos, dos movimentos sociais e dos "povos vencidos" (CALDEIRA NETO, 2009, não paginado). Segundo o autor, a partir da década de 1980 a comunidade acadêmica passou a dar mais atenção aos relatos orais, tendo como um dos focos de estudo a memória dos sobreviventes do Holocausto. "Foi quando ocorreu o amadurecimento da História Oral como campo/escola/tendência da historiografia, de forma com que surgiram neste momento algumas organizações voltadas à prática da História Oral” (CALDEIRA NETO, 2009, não paginado).

Apesar de reconhecida, a História Oral encontra certa resistência e desconfiança entre os historiadores, o que resulta das "formas arraigadas de se conceber a história e a validade de suas fontes" (FERREIRA, 1998, p. 1). Desta forma, “a consolidação da disciplina da história e a profissionalização do historiador no século XIX impuseram o domínio absoluto dos documentos escritos como fonte, em detrimento da tradição oral, expulsando a memória em favor do fato" (FERREIRA, 1998, p. 1).

A força da História Oral está, segundo Joutard (2000), em dar voz às pessoas que normalmente não a tinham, mostrando que cada indivíduo é ator da história. Mesmo quando há registros escritos, o oral revela realidades ausentes nos documentos. Joutard (2000) ressalta ser necessário reconhecer os limites da história oral: “as fraquezas da própria memória, sua formidável capacidade de esquecer, que pode variar em função do tempo presente, suas deformações e seus equívocos" (JOUTARD, 2000, p. 34).

Apesar das fraquezas apontadas por Joutard (2000), a História Oral pode, segundo Thompson (1992), contribuir para o resgate da memória nacional, pois ajuda a preservar a memória física e espacial, assim como a descobrir e valorizar a memória 
do homem. Isto porque "a memória de um pode ser a memória de muitos, possibilitando a evidência dos fatos coletivos" (THOMPSON, 1992, p. 17). Ou seja, como reforçam Matos e De Senna (2011, p. 96), a "fonte oral pode acrescentar uma dimensão viva, trazendo novas perspectivas à historiografia, pois o historiador, muitas vezes, necessita de documentos variados, não apenas os escritos".

Ao trabalhar-se sobre os dados disponibilizados nas redes sociais digitais, esse esquecimento pode ser minimizado, visto que os depoimentos ficam registrados, seja por escrito, áudio, vídeo e até mesmo em fotografias. Em texto na Revista de História da Biblioteca Nacional, o historiador José Carlos Sebe Meihy destaca que

as fontes orais são consideradas importantes por possibilitarem abordagens que vão além das informações filtradas por documentos oficiais e oficializados. É importante reconhecer na História os seres humanos e não tratar situações como se fossem movimentos institucionais. A humanização da História não ocorrerá sem a consideração dos seres viventes (MELO, 2011, não paginado). ${ }^{9}$

Uma forma atual de permitir essa humanização da História é fazer uso da internet, entendida como uma mídia cada vez mais presente na vida das pessoas, a qual "modifica e é modificada pelas relações e que pode ser usada como fonte de pesquisa para historiadores e afins" (CALDEIRA NETO, 2009, não paginado). Segundo o autor, quanto mais o acesso à internet se populariza como meio de comunicação, mais amplo fica o campo das relações humanas, tanto nos aspectos político-estatais, quanto das transações econômicas e comerciais, chegando até as relações pessoais e afetivas.

Ao proporcionar a troca de pensamentos e informações, feita em grande escala nas redes sociais digitais, segundo Dupas (2005), abre-se na internet um espaço inusitado a pessoas e ideias, as quais nem sempre teriam fácil circulação, mantendo-se na "ilegalidade". Dantas (2005) aponta que nas redes sociais digitais é constante o processo de produção de memórias sociais, permitindo um comprometimento com o passado (e seu registro, através das postagens) em um meio que normalmente se define como imediatista.

Joutard (2000) aproxima a História Oral desses novos produtos midiáticos quando afirma que

as novas tecnologias também multiplicam os documentos orais que não decorrem exatamente da história oral, mas aos quais precisamos dar atenção: os áudio-livros, as vídeo-cartas e, mais além, como integrar o conteúdo dos inúmeros fóruns da internet, ou das páginas de simples particulares da web? Paradoxalmente, voltamos à escrita, mas

\footnotetext{
${ }^{9}$ O texto é assinado por Alice Melo (2011), a partir de entrevista com o historiador.
} 
a uma escrita muito mais amplamente difundida, mesmo que hoje envolva apenas uma minoria (JOUTARD, 2000, p. 42).

Os apontamentos de Joutard indicam que documentos orais vão além de entrevistas, conversas e depoimentos, podendo ser também gravações audiovisuais e, ainda, registros escritos, os quais revelarão informações a respeito das situações pesquisadas.

Há questionamentos sobre o uso desses documentos orais disponibilizados a partir das novas tecnologias, devido à incerteza de sua veracidade. Sobre isso, Almeida (2011), reflete:

Trabalhar sob uma incerteza calculada não é novidade para o historiador, pois os métodos históricos não são totalmente precisos. As fontes "tradicionais" não são mais confiáveis do que as fontes digitais. Um documento impresso pode ser falso. Uma fotografia antiga pode ser fraudulenta. Um depoimento oral pode modificar os fatos. É normal para os historiadores trabalhar dentro de campos de possibilidades, utilizando métodos para reduzir as chances de erro. No futuro, é possível que sejam criados mecanismos mais precisos para verificar a autenticidade das fontes digitais. Contudo, enquanto tais procedimentos não se tornarem operacionais, a habilidade e a experiência do pesquisador continuarão determinantes na seleção das fontes mais confiáveis (ALMEIDA, 2011, p. 22-23).

Percebe-se que, apesar de escrita, a memória registrada nas redes sociais digitais tem valor de fala ao trazer o imediatismo desse tipo de plataforma de comunicação para o registro digital dos acontecimentos narrados a partir de um ponto de vista.

As reflexões apresentadas embasam a análise das postagens do perfil @ vozdacomunidade no Twitter durante a ocupação do Complexo do Alemão, em 2010, objeto de estudo deste artigo, buscando compreender o potencial das narrativas apresentadas nessa rede social digital enquanto elemento de História Oral.

Estudo de caso: no Twitter, a @vozdacomunidade relata a ocupação do Complexo do Alemão

O Complexo do Alemão é um conjunto de favelas localizado na Serra de Misericórdia, no Rio de Janeiro (RJ). A área tem esse nome devido ao primeiro proprietário da área, o polonês Leonard Kaczmarkiewicz, conhecido em 1920, época da aquisição, por “alemão". Na época, empresas e trabalhadores se instalaram na área, mas a ocupação começou efetivamente em 1951, quando Kaczmarkiewicz vendeu a área em lotes (O GLOBO, 2013, não paginado).

Em 2010, o governo da cidade do Rio de Janeiro iniciou ações para pacificar as 
favelas cariocas e retirar o comando do tráfico de drogas das áreas, contando, para tanto, com o apoio dos governos estadual e federal. Em 27 de novembro de 2010, as forças policiais e o Exército posicionaram-se nos 44 acessos do complexo. "Na tarde de sábado, o coronel Lima Castro, relações públicas da PM do Rio, chegou a dizer a jornalistas que os traficantes teriam até o por-do-sol para se entregarem. 'A proposta é de paz, mas se formos chamados à guerra, vamos responder com a mesma força', afirmou" (ESTADÃO, 2010, não paginado).

A ocupação do Complexo do Alemão iniciou por volta das $8 \mathrm{~h}$ do dia 28 de novembro de 2010. Segundo O Globo (2010a, não paginado), "as forças de segurança vasculham toda a comunidade em busca de traficantes. Dez toneladas de maconha foram apreendidas. Oito pessoas foram presas tentando fugir pela galeria de águas pluviais".

Toda a ação policial teve ampla cobertura pela mídia tradicional. Além da cobertura tradicional, com o envio de equipes de reportagem para acompanhar a ação, houve destaque, inclusive pela própria mídia, ao que foi relatado por três moradores do Complexo, que usaram uma das principais características do Twitter - seu caráter de tempo real -, que vem sendo potencializado pelo aumento da presença de smartphones conectados à internet.

Percebe-se que os usuários do Twitter podem usar o outflow não apenas para expressar opiniões ou contar detalhes do seu cotidiano, mas também para narrar acontecimentos relevantes. Este é o caso do Twitter@vozdacomunidade, criado por Renê Silva em 2009 para "falar com as pessoas da comunidade sobre quais problemas sociais estariam acontecendo e como eu pudesse entrar em contato com as autoridades para resolver esses problemas" (BLOG, 2011), sem sucesso.

Em 2010, quando ocorreu a ocupação do Complexo do Alemão, Renê inicialmente utilizou sua conta pessoal @Rene_Silva_RJ para relatar o que estava acontecendo na comunidade. Depois, optou por centralizar as informações no perfil do jornal, como mostra a Figura 1.

Figura 1 - Primeiro tweet da @vozdacomunidade sobre a ocupação do Complexo do Alemão Voz da Comunidade @vozdacomunidade-27 de nov de 2010

V(10)Z) Boa tarde! Vou começar a publicar as noticias deste twitter!!! Quem está atento?

Fonte: <https://twitter.com/vozdacomunidade/status/8559019341910016>. Acesso em: 10 set. 2015. 
Ao direcionar a publicação das informações para o perfil @ vozdacomunidade, ele identificou que (Figuras 2 e 3) muitas pessoas, de diferentes locais e status, estavam

falando daquilo que a gente publicava. [...] Continuei publicando o que acontecia, cada vez mais intensa porque o tiroteio começou a rolar, e eu falava toda a verdade do que estava rolando né. Daqui a pouco eu ligo a tv e vejo na Globonews falando do Twitter @ vozdacomunidade e me assustei: gente, como assim? Acabei de falar aqui no Twitter e já está na tv? Muito rápido essa parada. (BLOG, 2011).

Figura 2 - Tweet da @vozdacomunidade sobre a ocupação do Complexo do Alemão

Voz da Comunidade @vozdacomunidade.27 de nov de 2010

(V(1)Z)

A maioria das pessoas está seguindo o VOZ DA COMUNIDADE pra saber informações tempo real do que está acontecendo no Complexo do Alemão hoje

\section{2}

Fonte: 〈https://twitter.com/vozdacomunidade/status/8619903149932546〉. Acesso em: 10 set. 2015.

Figura 3 - Tweet da @ vozdacomunidade sobre a ocupação do Complexo do Alemão Voz da Comunidade @vozdacomunidade - 29 de nov de 2010 (V(1)Z) Olha Globnews falando da gente agora !!! hahahaha \#vozdacomunidade

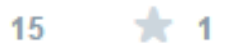

Fonte: <https://twitter.com/vozdacomunidade/status/9267148551626752>. Acesso em: 10 set. 2015.

Além de fornecer informações para os usuários do Twitter, a @vozdacomunidade foi usada como fonte para os veículos de comunicação ditos tradicionais, como televisão (descrito por ele) e jornais (impressos e em suas versões digitais), como mostra a Figura 4.

Figura 4 - Tweet do @jornalextra para o perfil @ vozdacomunidade sobre a ocupação do Complexo do Alemão 


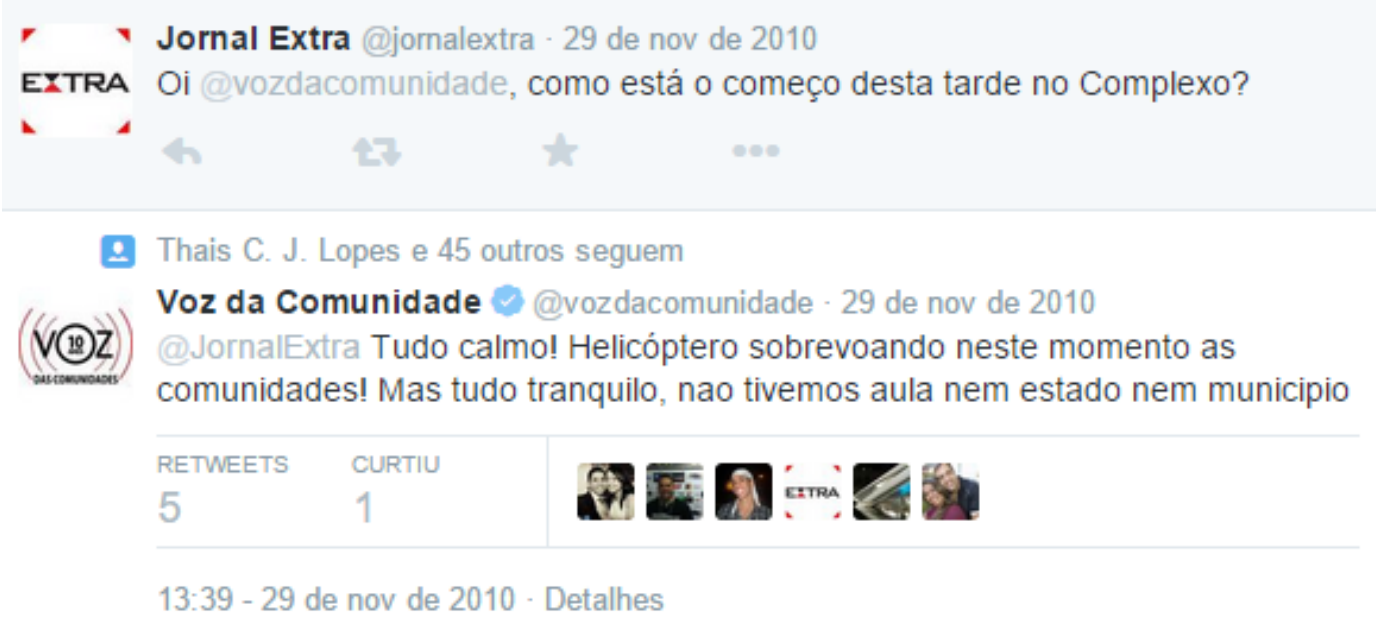

Fonte: <https://twitter.com/jornalextra/status/9269850509672449>. Acesso em: 10 set. 2015.

A proximidade entre o jovem e o fato permitiu, inclusive, que ele corrigisse informações da imprensa via Twitter, como ele conta: "a gente até corrigia algumas informações dadas na tevê, como as áreas que os helicópteros estavam sobrevoando, porque conhecemos melhor a comunidade" (O GLOBO, 2010b, não paginado).

A análise das Figuras 2, 3 e 4 corrobora a reflexão de Almeida (2011, p. 22), quando ele afirma que "as fontes 'tradicionais' não são mais confiáveis do que as fontes digitais". Isto porque mostra que a mídia impressa e televisiva, considerada uma fonte tradicional, baseou-se nas publicações da @vozdacomunidade no Twitter para produzir seu conteúdo, o qual já é utilizado como fonte historiográfica.

A partir dos estudos e análises realizados, é possível identificar outros pontos para discussão. Inicialmente, verifica-se a possibilidade de o Twitter ser fonte de História Oral, visto que, como mostra a Figura 5, por meio dele o usuário narra em primeira pessoa acontecimentos que podem ter valor para a história recente do Brasil, pois marca o momento exato do início da ocupação.

Figura 5 - Tweet da @vozdacomunidade sobre a ocupação do Complexo do Alemão
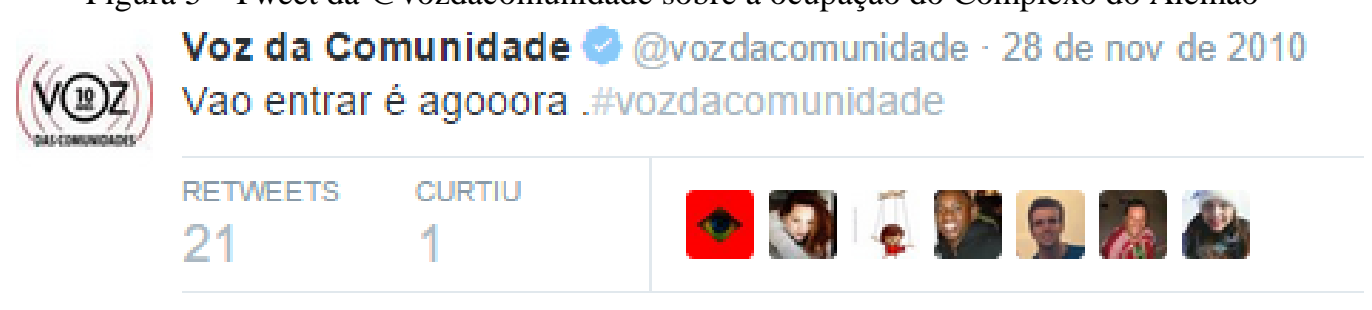

\section{7:54 - 28 de nov de 2010 - Detalhes}

Fonte: <https://twitter.com/vozdacomunidade/status/8821082324729856>. Acesso em: 10 set. 2015. 
Além disso, o conteúdo compartilhado mostra que Renê (assim como seus amigos) assume, em relação ao fato, uma posição privilegiada de visão de mundo e compreensão dos acontecimentos. As Figuras 6 e 7 reforçam a posição dos jovens de informantes privilegiados, o que não acontece com os repórteres destacados pelas empresas de comunicação para a cobertura.

Figura 6 - Tweet da @ vozdacomunidade sobre a ocupação do Complexo do Alemão

Voz da Comunidade @vozdacomunidade - 28 de nov de 2010

V(10) São muitos disparos, jornalistas de todas emissoras correm por toda rua procurando abrigo! Se cuide! \#vozdacomunidade

Fonte: 〈https://twitter.com/vozdacomunidade/status/8805733441208320〉. Acesso em: 10 set. 2015.

Figura 7 - Tweet da @ vozdacomunidade sobre a ocupação do Complexo do Alemão

Voz da Comunidade @vozdacomunidade.28 de nov de 2010

V(10) Nossa equipe está protegido ! Já falei \#vozdacomunidade nóis nao iriamos ficar correndo risco de morte pra noticiar aqui.

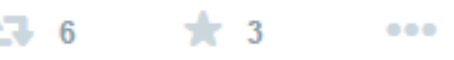

Fonte: <https://twitter.com/vozdacomunidade/status/8809001802276864>. Acesso em: 10 set. 2015.

Também se percebe que a correção de informações divulgadas pelos veículos de comunicação tradicionais feita por Renê indica a importância das fontes consideradas não tradicionais para o relato da História. Ao afirmar que "não imaginava que ia causar tanta repercussão, mas acho que foi porque estávamos twittando de dentro da comunidade, mostrando uma visão que ninguém tinha" (O GLOBO, 2010b, não paginado), Renê se coloca como parte do evento, em uma posição privilegiada de visão de mundo e compreensão dos acontecimentos - algo que um repórter que não conhecesse a região não teria.

Ao destacar que as ferramentas digitais de comunicação podem fazer parte dos documentos de História Oral, Joutard (2000) abre um novo campo de análise. Neste sentido, retoma-se Santaella e Lemos (2010), que apresentam o Twitter como um espaço colaborativo de difusão contínua de ideias, no qual questões podem ser livremente debatidas e respondidas, sendo assim um termômetro social e político e instrumento de resistência civil. 
Percebe-se, então, que os registros das redes sociais digitais, chamados também de big data, podem ser reconhecidos como elementos de História Oral. As pessoas usam seus perfis em redes sociais digitais para relatar, conversar, falar espontaneamente sobre determinados assuntos, retratando sua opinião sobre eles, o que pode ser usado para estabelecer parâmetros, identidades, posicionamentos sociais.

A reflexão de Ferreira (1998) remete às formas de registro apropriadas pelo Twitter, que inclui não só a palavra escrita, mas também sons, fotos e vídeos que são distribuídos livremente entre pessoas (LEMOS; LEVY, 2010), como mostra a Figura 8.

Figura 8 - Tweet da @vozdacomunidade sobre a ocupação do Complexo do Alemão

\section{Voz da Comunidade@ @vozdacomunidade.29 de nov de 2010 15:53 - estão revistando moradores que sobem a comunidade! \#vozdacomunidade http://twitpic.com/3bdy7u}

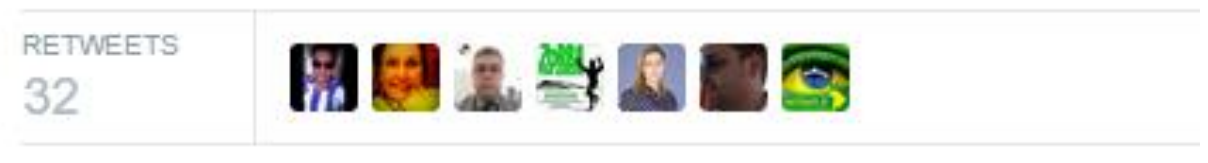

15:54 - 29 de nov de 2010 - Detalhes

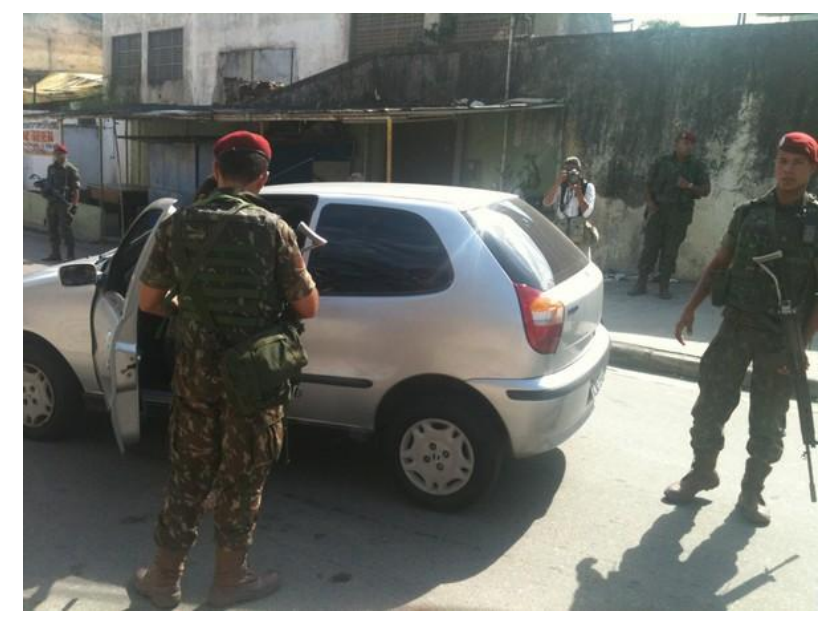

Fonte: <https://twitter.com/vozdacomunidade/status/9304097131859968>. Acesso em: 10 set. 2015.

Esta "liberação da emissão" permite que as pessoas, como participantes de um fato histórico, registrem o acontecimento e repercutam com outras pessoas. Também é importante frisar que os registros via Twitter permitem a aplicação de regras científicas de pesquisa, o que rompe a recusa de dar à história contemporânea o estatuto de história, questão que é tratada por Ferreira (1998):

No plano teórico, a história deveria ser identificada com o passado, o que excluiria o período mais recente. No plano metodológico, colocavam-se em questão as fontes contemporâneas, raras em razão dos limites legais para a consulta, e ao mesmo tempo superabundantes 
em virtude da ampliação da noção de arquivo. A história contemporânea tornou-se uma história sem objeto, sem estatuto e sem definição, algo ainda muito próximo, muito parcial e fortemente ideologizado pelo discurso universalista do Ocidente (FERREIRA, 1998, p. 2).

A reflexão apresentada neste artigo questiona este pensamento, apontando um objeto sobre o qual há a possibilidade de aplicação de um método de pesquisa, mesmo que em relação a fatos contemporâneos. $\mathrm{O}$ fato de ser um passado recente - mas ainda assim um passado - permite, também, o distanciamento necessário sobre o fato para a análise e busca de informações em diversas fontes que colaborem com a escrita da história.

Percebe-se, também, que os posts da @ vozdacomunidade no Twitter deram não apenas aos jovens, mas também - e principalmente - ao Complexo do Alemão, como um todo, uma possibilidade de fala. Essa posição remete a Dupas (2005), para quem a internet abre espaço para pessoas e ideias - e também seus pensamentos e impressões do mundo ao seu redor - que sem essa ferramenta de comunicação não teriam fácil circulação, mantendo-se na "ilegalidade" ou, nesse caso, na informalidade do boca-aboca local.

Ao dar voz "ao morro" a partir da visão de mundo dos moradores, compartilhada digitalmente, a mídia tradicional também colabora com um entendimento de que as redes sociais digitais podem servir de fonte, desde que a informação seja verificada e apurada. Da mesma forma, havendo esse cuidado, o pesquisador pode valer-se do mesmo material na historiografia.

\section{Considerações finais}

Este artigo buscou reconhecer a rede social digital Twitter como fonte para a construção da narrativa histórica, considerando que os tweets publicados pelos usuários podem ser fontes de História Oral. Entendeu-se, aqui, porque o Twitter não se resume a um espaço de publicação de opiniões, mas também pode ser usado para narrar acontecimentos.

Fez-se, neste artigo, o estudo do caso da ocupação do Complexo do Alemão, em 2010, a partir das publicações feitas pelo jornal @ vozdacomunidade. As reflexões realizadas permitiram verificar que o Twitter pode ser considerado uma fonte de História Oral ao assumir o papel de relato do cotidiano. Também houve a busca por 
apontar formas de uso das mídias sociais, em especial o Twitter, como espaços que garantam a validade do relato como fonte oral. Salienta-se a importância que teve a @vozdacomunidade como fonte de informações não somente para a comunidade do Complexo do Alemão, mas, inclusive, para a mídia oficial, a qual foi corrigida e abastecida pelo canal em diversas momentos.

História Oral dá voz aos que normalmente não a têm, como os esquecidos, excluídos ou derrotados, (JOUTARD, 2000) colocando-os como atores da história. É o que se percebeu nos tweets postados pela @vozdacomunidade durante a ocupação do Morro do Alemão, em 2010, nos quais os autores informam seus seguidores, inclusive pautando a mídia tradicional - que não apenas segue o conteúdo, mas também solicita informações. Joutard (2010) entende que esse uso das novas tecnologias de comunicação pelas pessoas "comuns" abre um novo campo de análise, no qual os registros das interações em redes sociais digitais podem ser reconhecidos como elementos de História Oral.

Considera-se que o Twitter, como rede social digital, pode ser utilizado na construção de narrativas históricas. Percebe-se, a partir do estudo apresentado, que o uso de ferramentas de comunicação digital (conceito que abrange também as redes sociais digitais) torna o mundo mais tecnológico, interligado e conectado. Além disso, as mudanças que tais ferramentas proporcionam - ao permitirem que novas pessoas e ideias ganhem espaço e voz, com alta circulação, como aponta Dupas (2005) - podem ser incluídas nas mudanças de entendimento, posicionamento e de referência dos estudos historiográficos relacionados à história do tempo presente.

Em sua origem, a Escola de Annales não deve ter previsto até onde o conceito de história mais abrangente e totalizante chegaria. Hoje, a história pode ser contada em tempo real, por diversas vozes, de diversos níveis de complexidade e influência. Os relatos publicados nas redes sociais digitais, a partir de pessoas "comuns", podem enriquecer e dar novos caminhos não apenas aos estudos historiográficos, mas também de outras disciplinas das Ciências Sociais.

\section{Referências}

ALMEIDA, Fábio Chang de. O historiador e as fontes digitais: uma visão acerca da internet como fonte primária para pesquisas históricas. Aedos - Revista do Corpo Discente do PPG-História da UFRGS. N. 8, v. 3, jan./jun. 2011. Disponível em: <http://www.seer.ufrgs.br/ index.php/aedos/article/view/16776/11939>. Acesso em: 18 fev. 2016. 
BURKE, Peter. A Escola dos Annales - 1929-1989 - A revolução francesa da historiografia. São Paulo: UNESP, 1992.

CALDEIRA NETO, Odilon. Breves reflexões sobre o uso da Internet em pesquisas historiográficas. 8 out. 2009. Disponível em: <http://hid0141.blogspot.com.br/2009/10/ breves-reflexoes-sobre-o-uso-da.html>. Acesso em: 18 fev. 2016.

DANTAS, Camila G. O passado em bits: questões sobre a reelaboração da memória social na Internet. In: ENCONTRO NACIONAL DE CIÊNCIA DA INFORMAÇÃO, 6., Salvador, 2005. Anais... Disponível em: <http://www.cinformanteriores.ufba.br/vi_anais/docs/CamilaDantas.pdf>. Acesso em: 18 fev. de 2016.

DUPAS, Gilberto. Atores e poderes na nova ordem global: Assimetrias, instabilidades e imperativos de legitimação. São Paulo: UNESP, 2005.

ESTADÃO. Polícia e Exército iniciam invasão no Complexo do Alemão. 28 nov. 2010. Editoria Política. Disponível em:

<http://politica.estadao.com.br/noticias/geral,policia-e-exercito-iniciam-invasao-nocomplexo-do-alemao,646417>. Acesso em: 02 fev. 2016.

FERREIRA, Marieta de Moraes. História oral: um inventário das diferenças In: (Org.). ENTRE-VISTAS: abordagens e usos da história oral. Rio de Janeiro: Fundação Getulio Vargas, 1998. p.1-13.

GARCÍA, Miguel del Fresno; DALY, Alan J.; SUPOVITZ, Jonathan. Desvelando climas de opinión por medio del Social Media Mining y Análisis de Redes Sociales en Twitter. El caso de los Common Core State Standards. REDES - Revista Hispana para el Análisis de Redes Sociales. Vol. 26, núm. 1, Junio 2015. p. 53-75. Disponível em: <http://dx.doi.org/10.5565/rev/redes.531>. Acesso em: 20 jul. 2015.

IBOPE. Internet é a primeira fonte de informações para $47 \%$ dos brasileiros, aponta estudo. 15 abr. 2014. Disponível em: <http://www.ibope.com.br/ptbr/noticias/Paginas/Internet-e-a-primeira-fonte-de-informacoes-para-47-dos-brasileirosaponta-estudo.aspx>. Acesso em: 10 fev. 2015.

ISRAEL, Shel. Introdução. In: . A era do Twitter - como a ferramenta de mídia colaborativa mais dinâmica da atualidade pode revolucionar seus negócios. Rio de Janeiro: Elsevier, 2010. p.1-9.

JOUTARD, Philippe. Desafios à história oral do século XXI. In: FERREIRA, Marieta (Org). História oral: desafios para o século XXI. Rio de Janeiro: Fiocruz, 2000. p. 3146.

LEMOS, André; LÉVY, Pierre. Da opinião pública à inteligência coletiva. In:

O futuro da internet: em direção a uma ciberdemocracia planetária. São Paulo: Paulus, 2010. p. 85-100.

MATOS, Júlia Silveira; DE SENNA, Adriana Kivanski. História Oral como fonte: problemas e métodos. Historiæ, Rio Grande, v. 2, n. 1, 2011. p. 95-108. Disponível em: <http://www.seer.furg.br/hist/article/view/2395/1286>. Acesso em: 15 fev. 2016. 
MELO, Alice. Diagnosticador do presente. Revista de História.com.br. 14 mar. 2011. Disponível em: http://www.revistadehistoria.com.br/secao/gente-dahistoria/diagnosticador-do-presente. Acesso em: 04 set. 2015.

O GLOBO. Pesquisadoras traçam a história da ocupação do Complexo do Alemão. 04 out. 2013. Editoria Rio. Disponível em: <http://oglobo.globo.com/rio/pesquisadorastracam-historia-da-ocupacao-do-complexo-do-alemao-10247995>. Acesso em: 30 jul.2016.

O GLOBO. Polícia invade Complexo do Alemão. 28 nov. 2010. Editoria Rio. 2010a. Disponível em: <http://oglobo.globo.com/rio/policia-invade-complexo-do-alemao2919504>. Acesso em: 02 fev. 2016.

O GLOBO. Renê Silva, jovem morador do Morro do Adeus, twittou em tempo real a invasão da polícia ao Complexo do Alemão. 29 nov. 2010. 2010b. Disponível em: <http://oglobo.globo.com/rio/rene-silva-jovem-do-morador-do-morro-do-adeus-twittouem-tempo-real-invasao-da-policia-ao-2918816>. Acesso em: 02 fev. 2016.

PORT, Eduardo. The power of now. 2015. Disponível em: <http://pt.slideshare.net/ DigiTalks/the-power-of-now-o-poder-do-agora>. Acesso em: 30 jul.2016.

SANTAELLA, Lucia; LEMOS, Renata. Inflow vs. Outflow: Twitter e microdesign de ideias. In: Redes sociais digitais: a cognição conectiva do Twitter. São Paulo: Summus, 2010, p. 63-88.

THOMPSON, Paul. A voz do passado. São Paulo: Paz e Terra, 1992.

THOMSON, Alistair. Aos cinquenta anos: uma perspectiva internacional da história oral. In: FERREIRA, Marieta (Org). História oral: desafios para o século XXI. Rio de Janeiro: Fiocruz, 2000, p. 47-66. 